\title{
An experimental research of dynamic characteristics for long wall shearer cutting unit gearbox in oblique cutting
}

\author{
Jue Wang ${ }^{1} \cdot$ Shiyao Song ${ }^{1} \cdot$ Peng $\mathrm{Li}^{1}$
}

Received: 3 April 2019/Revised: 28 October 2019/Accepted: 4 January 2020/Published online: 2 March 2020

(C) The Author(s) 2020

\begin{abstract}
Oblique cutting is a working condition in fully mechanized mining whose function is making it possible for coal shearer to cut coal wall. Coal shearer often exhibit large vibration amplitudes in oblique cutting since the shearer is forced to be bent. In this study, dynamic behavior in oblique cutting for the coal shearer cutting unit gearbox (SCUG) is investigated experimentally based on National Coal Mining Equipment Laboratory of China. A new long wall mining test set-up consists of a test coal shearer and other auxiliary machines is developed for operating long wall coal mining process. Realistic oblique cutting process is developed, and vibration response will be more accurate since both cutting loads and test machine in this experiment are realistic. A data-acquisition system consisting of sensors, channel conditioner and computer is developed to capture three-dimensional vibratory accelerations. A test matrix which included various combinations of key cutting load parameters is executed under realistic oblique cutting loads within a wide parameter range to establish database. Experimental data is analyzed in time, domain and time-frequency domains for investigating the rules of dynamic behavior for SCUG. Beat vibration phenomenon and the coupling of gear mesh frequencies are found in experiment, resulting in local resonance and reduce fatigue life of SCUG. The influence of cutting load on beat phenomenon and frequency coupling is demonstrated at the end, and some conclusions are obtained.
\end{abstract}

Keywords Experimental study · Coupling frequencies · Beat vibration · Coal shearer - Dynamic behavior

\section{Introduction}

Long wall fully mechanized coal mining consisting of coal shearer, hydraulic support, scraper conveyor and reversed loader is used commonly in China, as shown in Fig. 1. Among them, coal shearer is the most important due to the direct role in coal cutting. Hence, coal shearer can determine the production capacity of a coal mine (Wang et al. 2006; Xu 2005; Rui and Huang 2000). However, the reliability of coal shearer is very low and SCUG is a weak part with more than $30 \%$ failure times in total (Wei and Tian 2007; Wang 2015; Zhou and Mi 2011; Zhai 2014). Oblique

Jue Wang

wangjue4346@126.com

1 Department of Information Engineering, Liaoning Economic Vocational Technological Institute, 110122 Shenyang, China cutting (shown in Fig. 2) is a working condition whose function is making coal shearer to cut coal wall with the help of scraper conveyor (Li and Wang 2007). Coal shearer is forced to bent in oblique cutting. Therefore, analyzing dynamic behavior of SCUG in oblique cutting is essential for improving reliability of coal shearer.

Very little has been published on dynamic behavior of SCUG. Among them, a group of papers focused on dynamic behavior of gear transmission system and straight line cutting. Zhao and Ma (2013) and Zhao and Tian (2015) used empirical formula to simulate cutting load on drum, and finite element software was used for calculating the dynamic response and reliability of SCUG. Zhou et al. (2016) and Zhang and Wang (2016) established a theoretical dynamic model using lumped mass method. Dynamic behavior and reliability sensitivity of SCUG are investigated and discussed. Recently, Liu et al. (2015, 2016) Yi et al. (2018), Yang et al. (2017), Zhang 



Fig. 1 Fully mechanized coal mining system

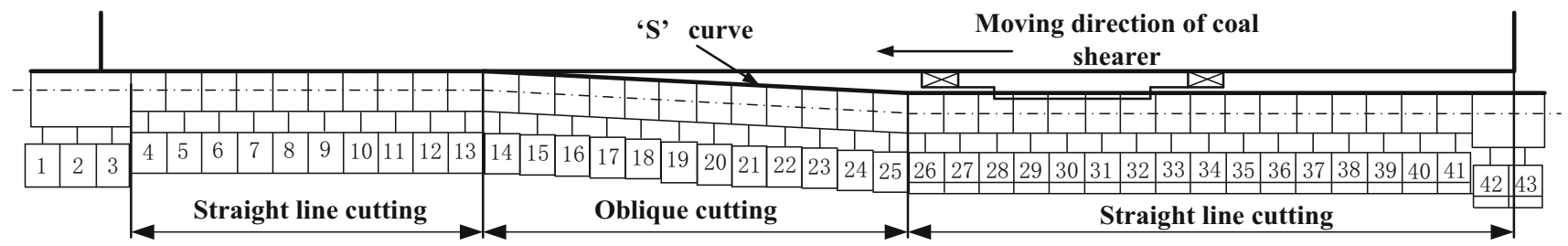

Fig. 2 Fully mechanized mining process

et al. (2018a, b) and Zhu et al. (2018) used test-bed to study dynamic response of SCUG for validating predicted results calculated by lumped mass dynamic model. Constant and sudden-change load on drum was applied on the test SCUG in experiment.

Literature on dynamic behavior in oblique cutting of SCUG is quiet sparse and limited. Mao et al. (2015) established mechanical analysis model of shearer in oblique cutting and calculated fatigue life of hydraulic rod in shearer. Yang et al. (2011) proposed force equations of shearer in oblique cutting and analyzed the influence of some key parameters on response of coal shearer. However, these mechanical models are all statics equations and dynamic behavior cannot be obtained.

To the best knowledge of the authors, no published study is available on experimental study of dynamic behavior for SCUG in oblique cutting. Accordingly, overall aim of this study is to investigate the dynamic behavior of SCUG in oblique cutting. Some vibration characteristics are observed in this experiment and the influence of several key parameters on dynamic behavior of SCUG are also discussed.

\section{Experimental set-up}

The experimental set-up designed and fabricated by National Energy Mining Equipment Laboratory of China for experimental investigation consists of a test coal shearer machine, other long wall mining equipment, test specimens and an accelerometer-based gearbox vibration data collection system, as shown in Fig. 3. Test coal shearer machine was identical with the ones working under coal mines. Components of experimental coal wall was made similar to real coal seam.

\subsection{Experimental variables}

According to Liu (2010), average chip thickness $h_{z}$, maximum chip thickness $h_{\max }$, average cutting resistance of each pick $Z_{i}$, total torque on drum $T_{d}$ are:

$h_{z}=\left(1-\cos \varphi_{b}\right) h_{\max } / \varphi_{b}$

$h_{\max }=100 v_{q} / S_{p} \omega$

$Z_{i}=\mathrm{A} h_{z}\left(0.3+350 b_{p}\right)$

$A \approx 150 f$

$T_{d}=\sum_{i=1}^{N} Z_{i} D_{i} / 2$

where $f, A, D_{i}, N, S_{p}, \omega, \varphi_{b}$ are consistence coefficient of coal seam, cutting resistance, diameter of pick tip, number of picks in cutting, pick number of each cutting line, rotation speed of drum, enclosed angle.

It can be seen from Eqs. (1)-(5) that: (1) traction speed $v_{q}$ impacts chip thickness $h_{z}$ and then impact cutting resistance $Z_{i}$ and torque on drum $T_{d}$. (2) Cutting depth can impact number of picks in cutting $N$ and then impact torque on drum $T_{d}$. Hence, cutting depths, traction speeds are selected as experimental variables. 


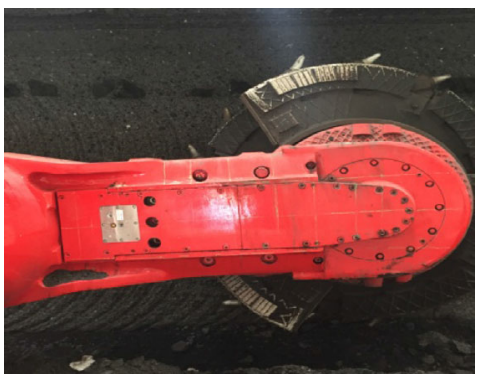

(a) Test SCUG

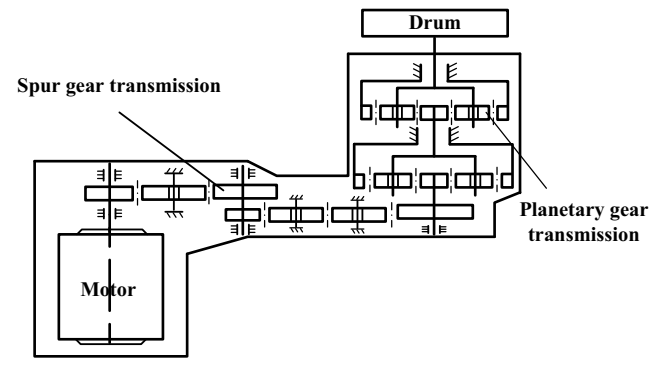

(b) Internal gear transmission system

Fig. 3 View of test SCUG and internal gear transmission system

\subsection{Measurement system and data acquisition}

An accelerometer-based measurement system was devised for measuring SCUG vibrations under coal cutting loads. Tri-axial accelerometers are mounted on SCUG near bearing holes of spur and planetary gear transmission, as shown in Fig. 4. Acceleration signals from the output of accelerometers were fed into 8-channel signal conditioner (PCB 483M92) and signals were amplified. Then, vibration signals were transmitted to an $\mathrm{A} / \mathrm{D}$ converter that digitized the analog signals at a user-defined sampling rate. Sample frequency in this experiment was set $8500 \mathrm{~Hz}$ due to meshing frequencies of gear transmission system in SCUG. Meshing frequencies and their multiples can be found in Zhang et al. (2018a).

\subsection{Test procedure}

In order to measure dynamic acceleration of SCUG accurately, test procedure was designed based on realistic oblique cutting in coal mines. Firstly, the left SCUG went oblique cutting from right to left with constant traction speed $1.5 \mathrm{~m} / \mathrm{min}$ when the right part went without cutting coal. Traction speed then reached to $3 \mathrm{~m} / \mathrm{min}$ when the right SCUG began going oblique cutting. Secondly, the right SCUG went oblique cutting with traction speed range

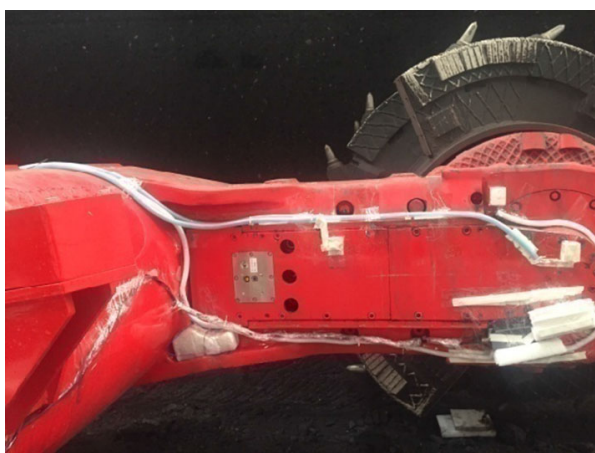

Fig. 4 The locations of sensors of 3-5 $\mathrm{m} / \mathrm{min}$ and cutting depth range of 0-600 $\mathrm{mm}$. Then coal shearer went straight line cutting from left to right with cutting depth range of $0-600 \mathrm{~mm}$ and constant traction speed $1.5 \mathrm{~m} / \mathrm{min}$. Finally, coal shearer reached to the right end of coal wall with traction speed $1.5 \mathrm{~m} / \mathrm{min}$ and cutting depth $600 \mathrm{~mm}$.

\section{Experimental results}

Measured vibration acceleration results with the time range of $0-840 \mathrm{~s}$ of both planetary and spur gear transmission of SCUG are shown in Figs. 5 and 6. It is seen that vibration acceleration increases significantly when oblique cutting began at $450 \mathrm{~s}$ in vertical, horizontal and axial directions. It is clear from the measured results that the acceleration peak is the largest for vertical direction and the lowest for axial direction in planetary gear transmission, while largest for horizontal direction in spur gear transmission. Within traction speed of $1.5 \mathrm{~m} / \mathrm{min}$ and cutting depth range of [100 mm, $600 \mathrm{~mm}$ ], the measured acceleration peak values of oblique cutting and straight line cutting are compared in Fig. 7. It is seen that peak vibration values in oblique cutting are close to and a little higher than that of straight line in most cases (except for $300 \mathrm{~mm}$ in Fig. 7b). The

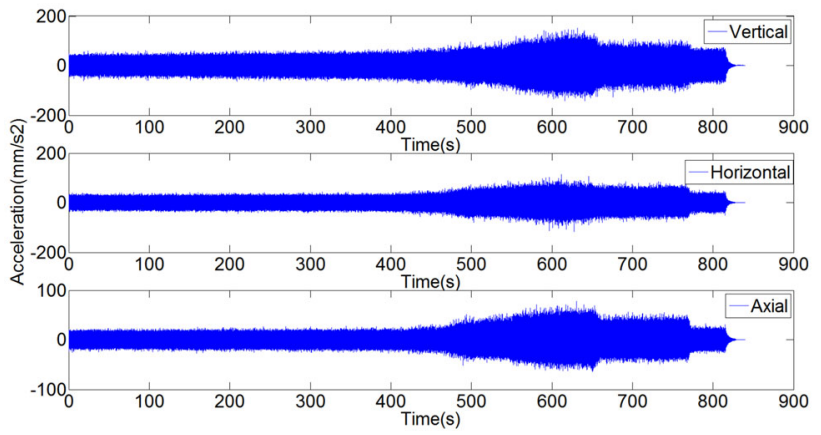

Fig. 5 Oblique cutting signal in planetary transmission 


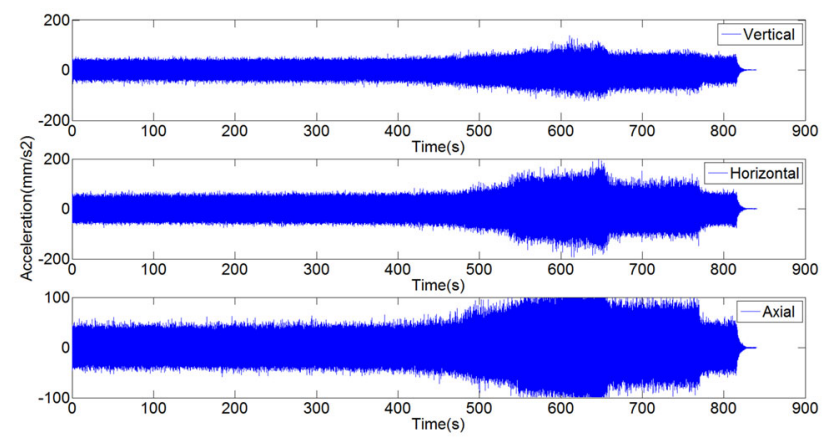

Fig. 6 Oblique cutting signal in spur gear transmission

findings show that oblique cutting is a worse working condition compared with straight line cutting.

\subsection{Beat vibration phenomenon}

In oblique cutting from about 450 to $650 \mathrm{~s}$, beat vibration phenomenon is observed and shown in Fig. 8a. FFT spectrum (Fig. 8b) shows that the two dominant frequencies $1230 \mathrm{~Hz}$ and $1400 \mathrm{~Hz}$ are close to each other. Beat phenomenon occurs when two harmonic vibration signals with too close space frequencies are excited by vibration source in terms of mechanical vibration theory. The conditions for beat phenomenon is:

$1<\max \left(\frac{w_{1}}{w_{2}}, \frac{w_{2}}{w_{1}}\right)<1.2$

where $w_{1}$ and $w_{2}$ are angular frequencies of two harmonic signals. The value of $\max \left(\frac{w_{1}}{w_{2}}, \frac{w_{2}}{w_{1}}\right)$ in this paper is 1.13 , which resides between 1 and 1.2. Therefore, the value satisfies the conditions given by Eq. (6) and the existence of beat phenomenon is verified.

For identifying the source of beat vibration frequencies $1230 \mathrm{~Hz}$ and $1400 \mathrm{~Hz}$, natural frequencies are obtained by finite element method. A finite element model is established for obtaining modal characteristics of gearbox housing using ANSYS (Fig. 9). This model includes 178,123 elements (Solid 185 in ANSYS) and 312,564 nodes. Young's elastic modules, yield limit, Poisson's ratio and density of housing were $200 \mathrm{GPa}, 300 \mathrm{MPa}, 0.3$, and $7800 \mathrm{~kg} / \mathrm{m}^{3}$, respectively. Full constraints were set on holes of hinged ears. Results show that the 23th order natural frequency is $1250 \mathrm{~Hz}$ and the 24th is $1390 \mathrm{~Hz}$, and they are very close to dominant frequencies $1230 \mathrm{~Hz}$ and $1400 \mathrm{~Hz}$. Hence, these two natural frequencies of SCUG are excited and beat vibration is caused by too close harmonic vibrations.

Vibration accelerations of planetary transmission and spur gear transmission are quite different because of different loads, meshing frequencies, gear parameters. Therefore, beat vibrations of different cutting loads for planetary and spur gear transmission are investigated, respectively. In this paper, the increase of cutting load is represented by cutting depth according to Eqs. (1)-(5). Figure 10 shows the time-frequency response of planetary transmission. It can be seen that the vibration energy is concentrated on high frequency band, and the low-frequency cutting load (lower than $50 \mathrm{~Hz}$ in Fig. 10) is very little. Hence, the vibration of SCUG is mainly caused by high-frequency gear meshing vibration. The large vibration of SCUG may be cause by two factors: one is the own large



(a) Planetary transmission



(b) Spur gear transmission

Fig. 7 Comparison of peak vibration accelerations between oblique and straight line cutting 




(a) Vibration acceleration response

Fig. 8 Beat vibration phenomenon in mearured vibration signals
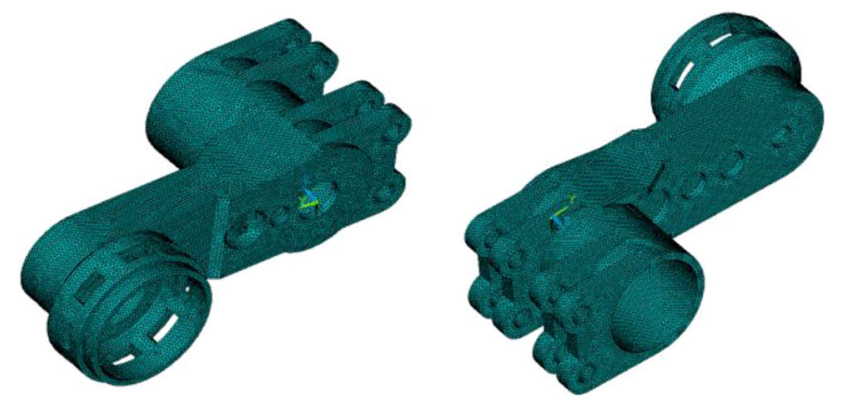

Fig. 9 Finite element model of the SCUG

vibration of gear transmission system and the other is resonance of SCUG caused by gear meshing vibration. Elliptic wire frames with back and red represent large vibration energy. Two large vibration frequency bands $(1230 \mathrm{~Hz}$ and $1400 \mathrm{~Hz})$ are found in $100 \mathrm{~mm}$ cutting depth, and vibration energy of $1230 \mathrm{~Hz}$ frequency band reduced when cutting depth increased to $300 \mathrm{~mm}$. When cutting depth increased to $600 \mathrm{~mm}, 1230 \mathrm{~Hz}$ frequency band disappeared and the vibration energy almost concentrate on $1400 \mathrm{~Hz}$ frequency band. Therefore, the beat vibration phenomenon of planetary transmission reduces with the cutting load on drum. Figure 11 shows the timefrequency response of spur gear transmission. It can be seen that the beat vibration is very weak in spur gear transmission and unchanged with cutting load comparing with planetary transmission. It is obvious that the



(b) FFT spectrum

frequency bands of spur gear transmission are more decentralized than that of planetary transmission and part of vibration energy is distributed in above $3500 \mathrm{~Hz}$ due to the higher meshing frequencies of spur gear transmission. Therefore, the weak beat vibration phenomenon of spur gear transmission may be caused by higher and decentralized meshing frequencies and the natural frequency $1230 \mathrm{~Hz}$ is not excited.

\subsection{Gear meshing frequency coupling}

Gear meshing frequency coupling phenomenon, which is a natural nonlinear dynamic characteristic of gear transmission system, occurs when meshing frequencies and their harmonics of other transmission stages appear in the frequency domain response of one transmission stage. Meshing frequency coupling phenomenon are found by some scholars (Walha et al. 2009; Wei et al. 2017; Liu et al. 2015) in gear transmission system and this phenomenon is also found in this paper. Frequency coupling can increase the number of excitation frequency and increase the probability of resonance for SCUG. The influence rules of cutting load on gear meshing frequency coupling phenomenon in planetary and spur gear transmission are investigated in this paper. Figure 12 shows the FFT spectra of planetary transmission. It can be seen that meshing frequencies and their harmonics of other transmission stages such as $f_{z 2}, 2 f_{z 2}+2 f_{m 1}, 2 f_{z 1}, 2 f_{z 2}$ appear in 


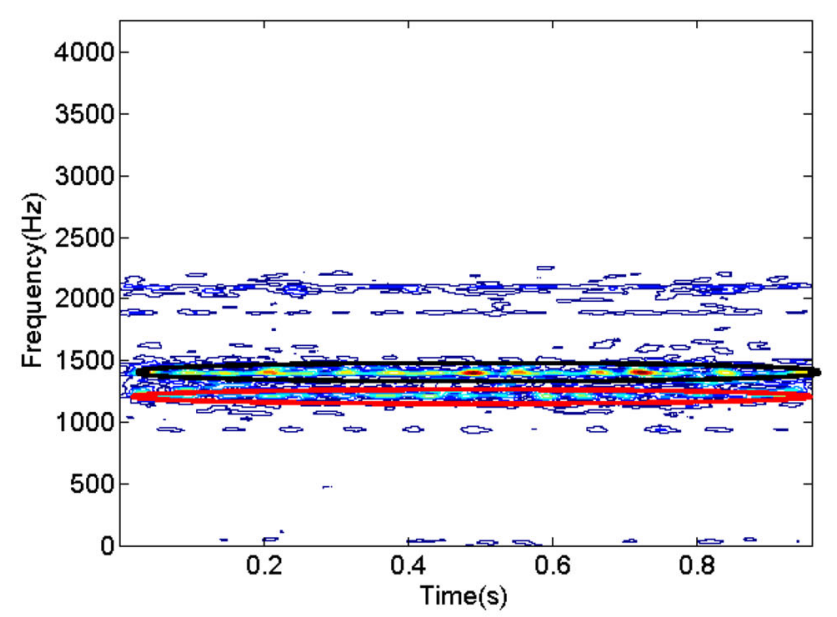

(a) $100 \mathrm{~mm}$ cutting depth

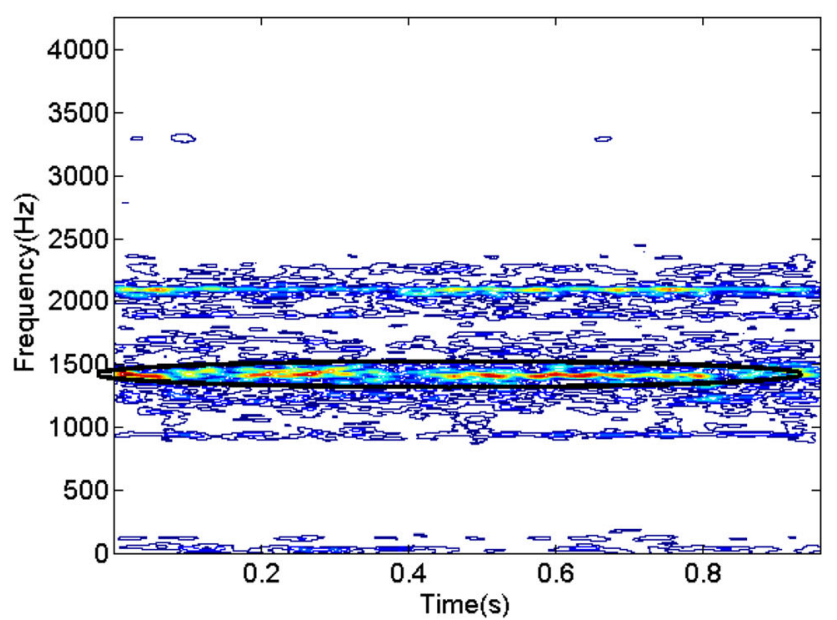

(b) $300 \mathrm{~mm}$ cutting depth

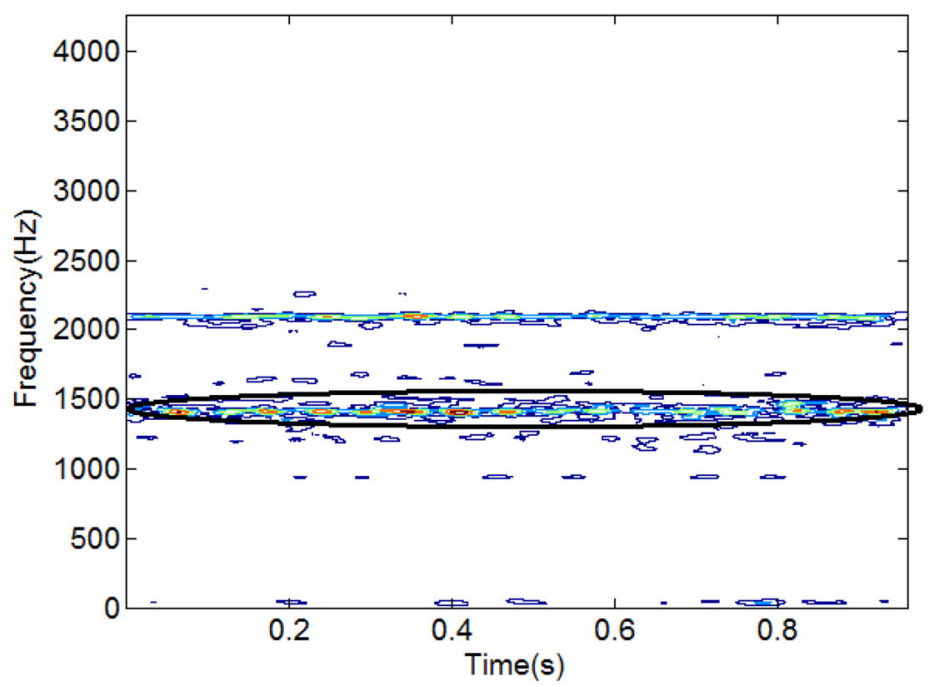

(c) $600 \mathrm{~mm}$ cutting depth

Fig. 10 Time-frequency response of planetary transmission

the first stage of planetary transmission. There are 4 coupling frequencies when the cutting depth is $100 \mathrm{~mm}$, and this number decreases to 3 and 2 when the cutting depth increases to $300 \mathrm{~mm}$ and $600 \mathrm{~mm}$, respectively. Therefore, the gear meshing frequency coupling phenomenon of planetary transmission reduces with the cutting load on drum. Figure 13 shows the frequency domain response of spur transmission. It can be seen that more coupling frequencies than planetary transmission are found in spur gear transmission such as $f_{z 1}, 2 f_{z 2}, 2 f_{z 1}, 2 f_{z 2}+2 f_{m 1}, 2 f_{z 1}+f_{z 2}$. The number of coupling frequencies keeps unchanged with the increase of cutting load. Hence, cutting load can't influence the gear meshing frequency coupling of spur gear transmission. In fact, no matter beat vibration or frequency coupling, cutting load has almost no impact on the dynamic response of spur gear but marked impact on planetary transmission. 


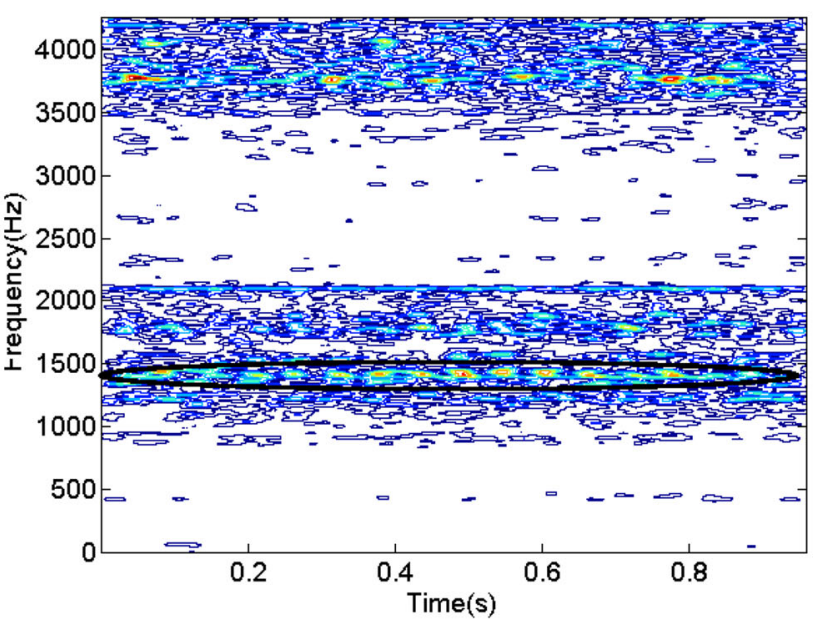

(a) $100 \mathrm{~mm}$ cutting depth

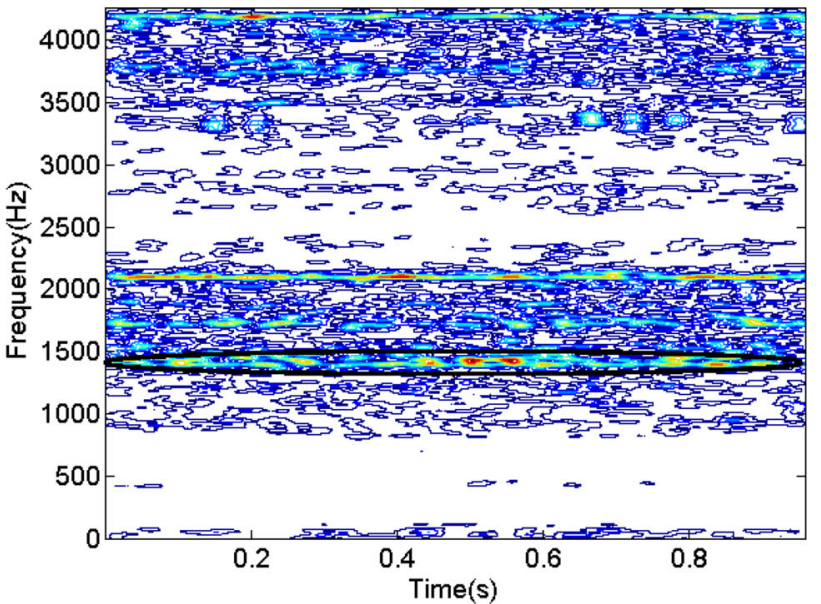

(b) $300 \mathrm{~mm}$ cutting depth

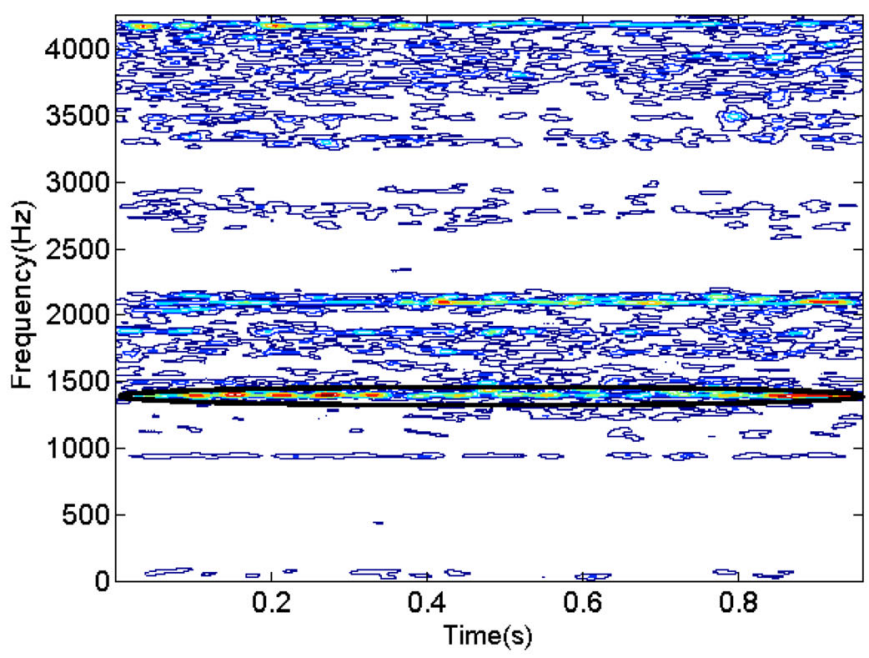

(c) $600 \mathrm{~mm}$ cutting depth

Fig. 11 Time-frequency response of spur gear transmission



(a) $100 \mathrm{~mm}$ cutting depth

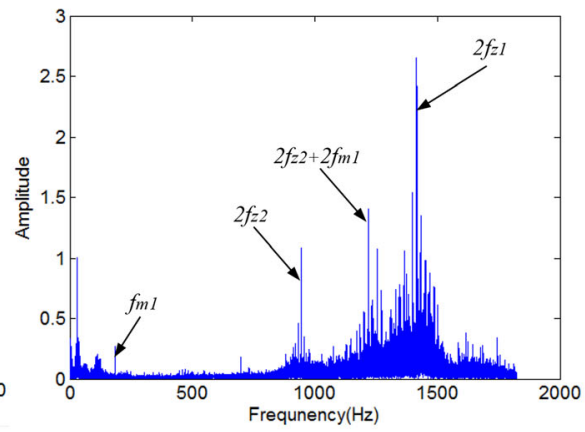

(b) $300 \mathrm{~mm}$ cutting depth



(c) $600 \mathrm{~mm}$ cutting depth

Fig. 12 Frequency coupling of planetary transmission 


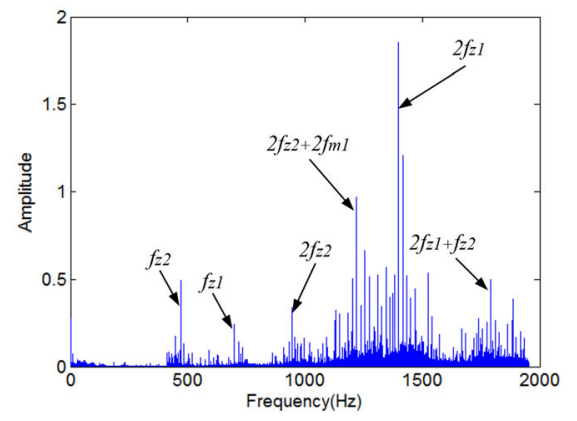

(a) $100 \mathrm{~mm}$ cutting depth



(b) $300 \mathrm{~mm}$ cutting depth

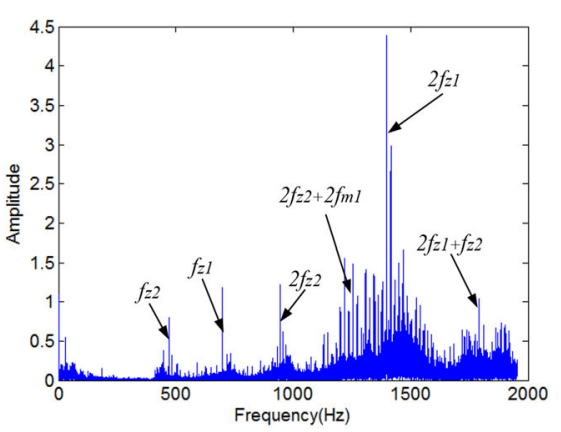

(c) $600 \mathrm{~mm}$ cutting depth

Fig. 13 Frequency coupling of spur gear transmission

\section{Conclusions}

(1) Coal cutting experiment of coal shearer is conducted in oblique cutting to investigate dynamic behavior of SCUG. Measured vibration accelerations were obtained by experiment and time domain analysis shows that oblique cutting is a worse working condition than straight line cutting.

(2) Vibration of SCUG is mainly caused by highfrequency gear meshing vibration.

(3) Beat vibration phenomenon of planetary transmission reduces with the cutting load. Spur gear transmission part of SCUG is little influenced by beat vibration.

(4) Coupling of gear meshing frequencies in planetary gear transmission reduces with the cutting load and the number of coupling frequencies keeps unchanged with the increase of cutting load in spur gear transmission. In fact, no matter beat vibration or frequency coupling, cutting load has almost no impact on spur gear transmission part of SCUG.

Acknowledgements This paper was supported by the National Basic Research Program of China (2014CB046303).

Open Access This article is licensed under a Creative Commons Attribution 4.0 International License, which permits use, sharing, adaptation, distribution and reproduction in any medium or format, as long as you give appropriate credit to the original author(s) and the source, provide a link to the Creative Commons licence, and indicate if changes were made. The images or other third party material in this article are included in the article's Creative Commons licence, unless indicated otherwise in a credit line to the material. If material is not included in the article's Creative Commons licence and your intended use is not permitted by statutory regulation or exceeds the permitted use, you will need to obtain permission directly from the copyright holder. To view a copy of this licence, visit http://creativecommons. org/licenses/by/4.0/.

\section{References}

Li B, Wang Q (2007) Coal Mine Machine. China Mining University, Xuzhou, pp 8-30

Liu C (2010) Working mechanism of double-drums coal shearer. Harbin Eng Univ Press 5:24-30

Liu C, Qin D, Liao Y (2015a) Electromechanical dynamic analysis for the drum driving system of the long-wall shearer. Adv Mech Eng 7(10):1-14

Liu H, Cai Z, Xiang C (2015b) Frequency coupling and dynamic behavior of nonlinear meshing force for two-stage planetary gears. J Vib Shock 34(19):14-18

Liu C, Qin D, Liao Y (2016) Dynamic analysis for the cutting electromechanical transmission system in the long-wall shearer. J Mech Eng 52(7):15-19

Mao J, Jiang P, Xie M (2015) Force analysis and life prediction of hydraulic rod on drum shearer under the condition of oblique cutting. Chin J Eng Des 22(1):96-98

Rui B, Huang Q (2000) Review and prospect of the 30 year development of China's shearers. Coal Mine Mechatron 5:36-40

Walha L, Fakhfakh T, Haddar M (2009) Nonlinear dynamics of a two-stage gear system with mesh stiffness fluctuation, bearing flexibility and backlash. Mech Mach Theory 44:1058-1069

Wang Z (2015) Causes of low reliability of mechanical system in electric traction shearer and improvement measures. Min Mach 43(2): $1-4$

Wang Q, Li B, Huang J (2006) Coal mining machine and support equipment. China Mining University, Xuzhou, pp 33-81

Wei Z, Tian F (2007) Methods and ways for improving reliability of shearer. Coal Mine Mach 28(6):11-13

Wei J, Zhang A, Qin D et al (2017) A coupling dynamics analysis method for a multistage planetary gear system. Mech Mach Theory 110:27-49

Xu X (2005) Technical status and development trend of coal mining machinery. Coal Zhongzhou 4:15-16

Yang L, Ge H, Jun H et al (2011) Analysis of force of shearer in various conditions. Coal Mine Mach 32(1):92-93

Yang Y, Fan H, Ma P (2017) Research on dynamic behavior for longwall shearer cutting transmission system with varying cutting speed. Int J Precis Eng Manuf 18(8):1131-1138

Yi Y, Qin D, Liu C et al (2018) Dynamic behavior of the electromechanical transmission system of a coal shearer in transient regimes. J Vib Shock 37(1):143-145 
Zhai Y (2014) Fracture analysis and improvement measures of ranging shell for shearer. Coal Mine Mach 35(10):192-195

Zhang Y, Wang T (2016) Jing Huang (2016) Fatigue reliability-based sensitivity design of planet gear for shearer rocker arm system. J Northeastern Univ (Nat Sci) 37(10):1427-1429

Zhang R, Zhang Y, Zhu L et al (2018a) Vibration characteristics for the rocker arm of shearer with gear meshing excitation. J Northeast Univ (Nat Sci) 39(1):109-112

Zhang Y, Zhang R, Zhu L, Zhao C (2018b) Analysis on dynamic behavior and influence factor of shearer rocker arm. J Vib Shock 37(9):114-119
Zhao L, Ma L (2013) Thin seam shearer reliability analysis and fatigue life prediction. J China Coal Soc 38(7):1288-1292

Zhao L, Tian Z (2015) Vibration characteristics of thin coal seam shearer. J Vib Shock 34(1):196-198

Zhou J, Mi L (2011) Fault and reliability analysis of shearer rocker arm gearbox. Shenhua Sci Technol 9(3):40-42

Zhou D, Zhang X, Zhang Y (2016) Dynamic reliability analysis for planetary gear system in shearer mechanisms. Mech Mach Theory 105:244-259

Zhu L, Zhang Y, Zhang R, Zhang P (2018) Time-dependent reliability of spur gear system based on gradually wear process. Eksploatacja I Niezawodnosc Maint Reliab 20(2):207-218 